\title{
A Needs Assessment for the Development of a Performance Appraisal System for Government Employees at the Provincial Statistical Office
}

\author{
Pornweenus Khoungsimma ${ }^{1}$, Songsak Phusee-orn ${ }^{2}$ \\ ${ }^{1}$ Nong Bua Lam Phu Provincial Statistical Office, Thailand \\ ${ }^{2}$ Faculty of Education Mahasarakham University, Mahasarakham Province, Thailand \\ Correspondence: Pornweenus Khoungsimma, Nong Bua Lam Phu Provincial Statistical Office, Thailand.
}

Received: May 29, 2018

doi:10.11114/jets.v7i3.3305

Accepted: January 30, 2019

Online Published: February 13, 2019

URL: https://doi.org/10.11114/jets.v7i3.3305

\begin{abstract}
This study aimed at two main objectives. The first objective is to perform a needs assessment for the development of a performance appraisal system for government employees. The second objective was to examine the guidelines on the development of the performance appraisal system for government employees. The findings of the study included the followings.

The performance appraisal system for government employees indicated a significant difference $\left(\mathrm{Z}^{*}=15.55\right.$, P-value $=$ $0.00)$ between the current conditions and expected conditions. The performance appraisal system for government employees was at a critical level of the need for development $\left(\mathrm{PNI}_{\text {modified }}=0.40\right)$.

The guidelines for the development of the performance appraisal system are the following. First, the inputs should clearly define the workload as well as the metrics and mutual evaluation criteria between the evaluator and the evaluates. Second, the process of the performance appraisal system should be conducted in the using an evaluation committee. A periodic performance monitoring system can be used to review the scoring rubrics of all evaluators. Third, the output of the performance appraisal report must show a clear scoring scale. Suggestions should be presented to tell the evaluator what has been observed. Fourth, feedback can divide government employees into 3 groups: 1) very good and excellent, admire the past performance, 2) good and fair, focus on acceptable and must-be-improved behaviors, and 3) must-be-improved, focus on what needs to be improved to make better performance as soon as possible.
\end{abstract}

Keywords: needs assessment, performance appraisal system, statistical office, government employees

\section{Introduction}

The government employees at the Provincial Statistical Office have three types of duties and responsibilities: academic statistics, statistical survey operations, and administration. The contract staff are on duty for 4 years. During the contract, the Provincial Statistical Office will evaluate the staff two times a budget year: 1) between October 1 and March 31 of the first year, and 2) between April 1 and September 30 of the same year. The evaluation process is very important to the Provincial Statistical Office because it is not only a process of determining how well employees do their jobs relative to a standard but of communicating that information to them. (Mathis and Jackson 2010, p. 320). As a result, the government employees can apply their knowledge and skills better to their duties. The results are also to determine if the compensation is appropriate to the performance. The performance appraisals are used to assess an employee's performance and provide a platform for feedback about past, current, and future performance expectations (Mathis and Jackson 2010, p. 329) and the performance appraisal possess must have reliability and validity. However, there are several weaknesses of the current performance appraisal for government employees.

The weaknesses of performance appraisal systems (Mathis and Jackson 2010, p.349-347 ; Gomez-Mejia et al. 2012, p.235 ; Lussier and Hendon 2012, p.307-306 ; Mondy and Martocchio 2012, p.251-249 ; Noe et al. 2012, p. 386 ) are often caused by: (1) an appraiser's discomfort with the performance evaluation, especially when poor performance is involved, (2) the lack of objectivity such as halo error, horn error, leniency, strictness, and median trend evaluation, (3) recent behavioral biases such as employees' behaviors suddenly improving during the period prior to the evaluation, (4) stereotyping when applying a personal feeling to the evaluation affecting the results of the evaluation, and (5) an incorrect evaluation which results in bias; for example, supervisors may simply "favor" one employee over another and overestimate his/her performance. 
Developing the performance appraisal system for government employees at the Provincial Statistical Office consists of four parts: Input, Process, Output and Feedback. If the problems with a performance appraisal system are known, priorities can be set to resolve the problems as soon as possible. The system can be modified to become an efficient system for evaluating the performance of government employees. The needs-assessment can provide relevant information to the Provincial Statistical Office in order to identify the issues of the performance appraisal system. The process includes comparing the current condition to the desired condition, defining the problem or problems, understanding the behaviors and mechanisms that contribute to current condition, determining if and how specific behaviors and mechanisms can be changed to produce the desired condition, developing solution strategies, and building support for action (Sleezer et al. 2014, p. 17). When we identify and work on needs, decisions about how resources are allocated have to be made. Unless new resources can be located, available human, fiscal, and material resources will be reallocated from one part of the workplace to another (Altschuld and Kumar 2010, p. 20). The needs-assessments should be a systematic process to guide decision making as well as to provide justification for decisions before they are made. After all, it is scalable for any size, timeframe, or budget of a project. A replicable model can be offered and applied by learners or experts (Watkins et al. 2012, p. 25).

The results of this study show differences between what should be and what it actually is. Four problematic conditions of the performance appraisal system were identified showing the need for guidelines in the development of a performance appraisal system for government employees at the Provincial Statistical Office.

\section{Objective of the Study}

This study aimed to conduct a needs assessment for the development of a performance appraisal system for government employees at the Provincial Statistical Office as well as the guidelines for the development of the performance appraisal system for government employees at the Provincial Statistical Office.

\section{Method}

\subsection{Sampling Design}

1.The sample for the needs-assessment on the development of the performance appraisal system included the population of 1,154 government officers and government employees at the Provincial Statistical Office. The sample consisted of 291 government officers and government employees. The sample size was determined using the Krejcie and Morgan Table (1970, p. 607-610). The sampling design was stratified random sampling. To eliminate sampling errors, 360 individuals were provided the questionnaire; 322 questionnaires were returned representing $89.44 \%$.

2. The study of guidelines for the development of the performance appraisal system for government employees used purposive sampling consisting of 20 experts, three measurement and evaluation experts, and 17implementation experts.

\subsection{Research Tools}

1. The Performance Appraisal System Questionnaire used for the needs assessment was divided into two parts. One was general information of the respondents' demographics. The other was opinions of the performance appraisal system of government employees. It was a 5-point rating scale where each question was divided into two parts: current conditions and expected conditions. The index of Item Objective Congruence (IOC) was used to evaluate the content validity based on 5 experts' ratings on the item relevance. It was found that the values between 0.60 and 1.00 were to be improved according to the experts' recommendation. The lower values were to investigate the reliability of the responses given to the questions. The assessment tool was tested with 30 government officers and government employees who were not subjects. The discriminant indices ranged from 0.34 to 0.94.The Cronbach's Alpha Coefficient of the assessment tool was .0 .99

2. Structured interviews were used for the development of guidelines for the performance appraisal system. The structured interviews were based on the findings from the needs assessment on the development of the performance appraisal system. The index of item objective congruence was used to evaluate the content validity based on 5 experts' ratings on the item relevance. It was found that the values between 0.60 and 1.00 indicated that improvement was needed based on the experts' recommendation.

\subsection{Data Analysis}

1. The data on the needs assessment of the development of the performance appraisal system were analyzed with the mean $(\bar{X})$ and standard deviation (S.D.) for both the current conditions and expected conditions. The differences of the opinions for the performance appraisal system of government employees between the current conditions and expected conditions were examined by using the Wilcoxon Signed Ranks Test and the differences of the priority needs index classified by job positions were examined by using the Mann-Whitney U test 
2. The Priority Needs Index ( $\mathrm{PNI}_{\text {modified }}$ ) was used to prioritize the findings from the needs-assessment to develop a performance appraisal system. If $\mathrm{PNI}_{\text {modified }}$ values were equal to or greater than 0.30 , it would indicate that the system needed to be developed. If the $\mathrm{PNI}_{\text {modified }}$ values were greater than or equal to 0.50 , it would indicate that system development was urgently needed. (Wongvanich 2015, p. 279)

3. Content analysis was used to analyze the data on the guidelines for the development of the performance evaluation system for government employees.

\section{Results}

\subsection{The Needs Assessment on the Development of the Performance Appraisal System}

This study suggested that there were 4 needs for the development of the performance appraisal systems: (1) inputs on planning and preparation, (2) process of the performance appraisal system to be implemented, (3) outputs on the result of the performance appraisal system, and (4) feedback on the performance report, review, and discussion of evaluation results.

Overall, the government employees' opinions for the performance appraisal system indicated a significant difference $\left(Z^{*}=15.55, \mathrm{P}\right.$-value $\left.=0.00\right)$ between the current conditions and expected conditions. The performance appraisal system for government employees was at the critical level of the need for development $\left(\mathrm{PNI}_{\text {modified }}=0.40\right)$. When considering each aspect, it was found that there were the needs for development. When the needs were prioritized for development based on $\mathrm{PNI}_{\text {modified }}$ values, the feedback was highest priority $\left(\mathrm{PNI}_{\text {modified }}=0.46\right)$ followed by process $\left(\mathrm{PNI}_{\text {modified }} 0.41\right)$ and output $\left(\mathrm{PNI}_{\text {modified }} 0.38\right)$, respectively. The lowest priority was input $\left(\mathrm{PNI}_{\text {modified }}=0.36\right)$. The details were as follows:

1. The inputs, the opinions for the performance appraisal system of government employees indicated significant difference $\left(Z^{*}=15.23, \mathrm{P}\right.$-value $\left.=0.00\right)$ between the current conditions and expected conditions. The inputs had three top priorities for the development as follows: the credence of each evaluator $\left(\mathrm{PNI}_{\text {modified }}=0.46\right)$, the forms for evaluations $\left(\mathrm{PNI}_{\text {modified }}=0.44\right)$, and the number of evaluators $\left(\mathrm{PNI}_{\text {modified }}=0.43\right)$, respectively.

2. The process, the opinions of the performance appraisal system of government employees indicated significant different $\left(\mathrm{Z}^{*}=15.20, \mathrm{P}\right.$-value $\left.=0.00\right)$ between the current conditions and expected conditions. The process had three top priorities for the development as follows: opportunity to ask questions about the performance appraisal scores $\left(\mathrm{PNI}_{\text {modified }}=0.53\right)$, feedback on a-performance appraisal process $\left(\mathrm{PNI}_{\text {modified }}=0.51\right)$, and records of behavior $/$ competency $\left(\mathrm{PNI}_{\text {modified }}=0.50\right)$, respectively.

3. The output, the opinions about the performance appraisal system of government employees were significantly different $\left(Z^{*}=15.20\right.$, P-value $\left.=0.00\right)$ between the current conditions and expected conditions. With the form of performance appraisal report was the most needed for the development of clarity, comprehensiveness, and comprehensibility $\left(\mathrm{PNI}_{\text {modified }}=0.49\right)$, the suggestions for the better performance $\left(\mathrm{PNI}_{\text {modified }}=0.45\right)$, and the description of performance appraisal scores $\left(\mathrm{PNI}_{\text {modified }}=0.43\right)$, respectively.

4. The feedback, the opinions for the performance appraisal system of government employees indicated significant difference $\left(Z^{*}=15.30, \mathrm{P}\right.$-value $\left.=0.00\right)$ between the current conditions and expected conditions. The feedback had three top priorities for the development as follows: the application of the evaluation result for planning the trainings of government employees ( $\mathrm{PNI}_{\text {modified }} 0.60$ ), the application of the evaluation result for coaching government employees $\left(\mathrm{PNI}_{\text {modified }} 0.52\right)$, and the application of the evaluation result for determining transfers or job assignments $\left(\mathrm{PNI}_{\text {modified }}=\right.$ $0.48)$, respectively.

Details are shown in Table 1.

Table 1. The results of the needs assessment on the development of the performance appraisal system at the Provincial Statistical Office

\begin{tabular}{|c|c|c|c|c|c|c|c|}
\hline \multirow{2}{*}{ System } & \multicolumn{2}{|c|}{ current condition } & \multicolumn{2}{|c|}{ desired condition } & \multirow{2}{*}{$Z^{*}$} & \multirow{2}{*}{ P-value } & \multirow{2}{*}{ PNI modified } \\
\hline & $\overline{\mathrm{X}}$ & S.D. & $\overline{\mathrm{X}}$ & S.D. & & & \\
\hline Input & 3.15 & 0.85 & 4.30 & 0.42 & 15.23 & $0.00^{*}$ & 0.37 \\
\hline Process & 3.33 & 0.91 & 4.69 & 0.44 & 15.20 & $0.00^{*}$ & 0.41 \\
\hline Output & 3.37 & 0.86 & 4.63 & 0.47 & 15.20 & $0.00^{*}$ & 0.38 \\
\hline Feedback & 3.24 & 0.98 & 4.74 & 0.45 & 15.30 & $0.00^{*}$ & 0.46 \\
\hline Overall & 3.27 & 0.84 & 4.58 & 0.38 & 15.55 & 0.00* & 0.40 \\
\hline
\end{tabular}

$* \mathrm{P}<0.05$

When the need for developing performance appraisal systems between the government officers (evaluators) and the government employees (evaluates) was compared, it was found that the results of the needs-assessment indicated no significant difference ( $\mathrm{p}$-value $>0.05$ ) between the government officers and the government employees. The whole 
group agreed that the performance appraisal system for government employees at the Provincial Statistical Office needed to be developed. The details are shown in Table 2.

Table 2. The results of the needs assessment on the development of the performance appraisal system for government employees at the Provincial Statistical Office classified by job positions

\begin{tabular}{l|c|c|c|c}
\hline \multirow{2}{*}{ System } & \multicolumn{2}{|c}{ PNI $^{*}$} & \multirow{2}{*}{$\mathrm{Z}^{*}$} & P-value \\
\cline { 2 - 5 } & Government officers (n=95) & $\begin{array}{c}\text { Government Employees } \\
(\mathrm{n}=227)\end{array}$ & -1.37 & 0.172 \\
\hline Input & 0.41 & 0.35 & -0.21 & 0.831 \\
\hline Process & 0.40 & 0.40 & -0.42 & 0.677 \\
\hline Output & 0.35 & 0.38 & -0.82 & 0.414 \\
\hline Feedback & 0.48 & 0.44 & $\mathbf{- 0 . 4 4}$ & $\mathbf{0 . 6 6 1}$ \\
\hline Overall & $\mathbf{0 . 4 1}$ & $\mathbf{0 . 3 9}$ & & \\
\hline
\end{tabular}

3.2 Guidelines for the Development of Performance Appraisal Systems

From the needs assessment on the development of the performance appraisal system for government employees at the Provincial Statistical Office, the experts proposed guidelines for the development of the performance appraisal system as follows.

1. Input, at the beginning of each year, the workload must be clarified with clear documentation of the assignment. The workload must be accepted by government employees. Then, the metrics or indicators of the performance for each government employee should not be the same because the workload is different among government employees. The evaluation criteria must be in line with the 2011 performance appraisal guidelines on at least 2 evaluation components: "behaviors" and " results". The proportion of the results must be not less than $80 \%$.

Determining the number of evaluators and the weight of each evaluator should comply with the 2011 performance appraisal guidelines for the evaluation of the performance among government employees. The kind of performance evaluation, the factors and the weighted score will be determined according to the agreement between the supervisors and the evaluates to be consistent with the responsibilities stated in the employment contract. After determining the indicators and the indicators agreed on among the government employees, the person responsible for the task (supervisor) and the person responsible for the work (evaluator) are determined. One indicator may be evaluated by more than one evaluator because some workload at the Provincial Statistical Office may involve academic statistics, statistical survey operations, and administration. When there is more than one person responsible for the task, the weighted score should be based on the workload and assessed by related evaluators. Several evaluators may assess a single employee, but the number of evaluators and their scores are weighted must be clarified. Self-rating should be included in addition to the evaluator's evaluation to lessen the omission in the evaluation. Peer-Rating among government employees can be used to rank the highest to the lowest ranking performers. To avoid over-rating or under-rating, the peer-rating should not be the leading tool in the evaluation. Instead, it should only be a baseline for evaluators. The bureaucracy does not depend on profits, but does depend on recognition of their work by the supervisors. Government employees may exaggerate over-react to the results of the performance if the peer-rating is applied as the leading method. There must be some mutual agreement among parties in ranking because salaries are affected.

The evaluation form must cover both results and behaviors. There should be additional sections for comments from each evaluator on each topic along with a conclusion at the end of the evaluation. The evaluation forms should provide space for the evaluates to write his or her opinion. There should be a variety of scoring criteria especially in the evaluation of competency. A clear form must include in Scoring Rubrics, both Holistic and Analytic Rubrics.

2. Process, the performance appraisal should be conducted using an evaluation committee. After evaluating the performance, all ratings from all evaluators must be reviewed. Everyone must have a consistent evaluation result to verify the accuracy of the results. A systematic monitoring of performance over time with the employees' monthly performance report with the format of the recording must be clear and easy to maintain.

The opportunity for government employees to provide feedback / comment on the procedures or performance appraisal process should be in the form and discussed in a joint meeting between evaluator and evaluates at the beginning of the year to allow government employees to negotiate indicators and scoring rubric to avoid the later resistance to the evaluation criteria.

Recording job behaviors / competencies is required. Description of competency among government employees must should delineate relevant workplace behaviors and good performance. The descriptions of competency should not be overwhelming because government employees (evaluates) may lack orientation. If the descriptions are concise, each performance tends to be more relevant to the actual performance. 
Discussion about performance appraisal scores after the evaluation results are derived requires the evaluators to provide the documentation on the results of the evaluation. The documentation is from periodic recording from the beginning of the year. There should be a form with short questions for the employees to answer and review their past performance in order to reduce feelings of resistance to evaluation results. Before the meeting or talking about the performance, a copy of the evaluation result should be provided to the staff in advance to be reviewed, considered and prepared before discussing the results. The right time for the appointment such as the last hour of the day or Friday afternoon can avoid resentment or conflict among government employees, and supervisors. Lastly, there should be appropriate indicators, evaluation criteria, and a clear assessment form in the process. These are the most important things and they should be started at the beginning of the evaluation year. The evaluator can use the indicators to describe the details for the evaluation score to make the evaluation results accepted.

3. Outputs, the performance appraisal report must show scores from each indicator with clear scoring rubrics to show the results of the evaluation from the beginning of the year. What are their practices? How were they doing on their tasks? Have they performed their responsibilities well? The language of the report should be easy to understand and useful for government employees' development such as identifying groups of employees for training purposes or modification of duties. The report must be provided to the government employees as soon as possible to prevent dissatisfaction with the delayed results of the evaluation causing doubts in the evaluation process. The plan can be made in advance to inform the employees about the date of the report on the evaluation results.

Providing feedback on performance appraisal reports should be realistic and based on the results of the evaluation. The instruction should be provided on what to improve with an easy-to-understand language. There are three key elements to any performance assessment: the particular strengths displayed by the individual, the most critical problems or the areas of needed improvement, and the most important needs of the individual's future development for the organization. How to explain the reasons for rating in the performance appraisal report using clear indicators and evaluation criteria. There should be facts or examples on a factual basis to support the results provided by the evaluators. Reasons must be clearly written out and explained, so the result can be more reliable and more accepted.

4. Feedback is important to the performance appraisal because feedback shows the strengths and weaknesses of government employees and help identify groups of government employees for planning, training, coaching, assigning work, or transferring. However, the feedback about performance is considered a communication between supervisors (giving feedback) and government employees (receiving feedback) to lead them to improvement. The increase of work efficiency helps meet the goals of the agency. There are three groups of staff. The first group is very good and excellent. The second group is good and fair. The last group is must improve. All three of these groups will not have the same feedback. The first group should focus on the past performance. The second group is provided both good and bad feedback, but the group will focus on what should be improved. The third group focuses on what needs to be improved as soon as possible.

Finally, every government employee writes a performance improvement plan, and it should be done at least twice a year: between October 1st and March 31st of the following year, and between April 1 and September 30 of the same year. The performance report, performance review, and discussion of evaluation results will inform government employees. The plan will be used to provide feedback to government employees on planning, training, coaching, and making decisions for assigning work to government employees or transferring duties.

\section{Discussion}

The researcher divides the discussion into two parts:

\subsection{The Needs Assessment for the Development of the performance Appraisal System}

Overall, the performance appraisal system for government employees at the Provincial Statistical Office needs to be developed. As a result, the Provincial Statistical Office should consider whether the evaluation system meets the mission and goals of the organization. The criteria for evaluation should be clearly stated. The tools used in evaluating should be fair and meet the standard of open communication between the evaluators and evaluates. The ongoing evaluation process can make the performance evaluation system more reliable, accurate, and accepted (Lussier and Hendon 2012, p. 287-288; Mondy and Martocchio 2012, p. 252-254; Noe et al. 2012, p. 348-350). The details are as follows:

1. Inputs need to be developed with the top three most priorities including the weighted score of each evaluator, the evaluation form, and the number of evaluators, respectively. If our method of measurement is not valid and reliable, then it makes no sense to use it (Lussier and Hendon 2012, p.287). Performance appraisal forms are maximally effective when they are used to highlight an employee's performance from the last review, or date of hire, to the present, in relation to the requirements and responsibilities as identified in the job description (Diane 2008, p. 59). Many times, evaluation forms may be too general in nature to be of value for modifying workplace behaviors because we want the 
form to serve for a large number of different types of jobs. This can create significant problems in the performance appraisal process (Lussier and Hendon 2012, p. 280).

2. Process has three top priorities to be developed including opportunity to ask questions about performance appraisal scores, feedback on performance appraisal process, and records of behavior /competency, respectively. Since most employees have a strong need to know how well they are performing, a good appraisal system will provide highly desired feedback on a continuing basis. There should be few surprises in the performance review. Continuous feedback is vitally important to help direct, coach, and teach employees to grow and improve performance. If the company does not have a formal grievance procedure, it should develop one to provide employees an opportunity to appeal appraisal results that they consider inaccurate or unfair. They must have a procedure for pursuing their grievances and having them addressed objectively) Noe et al. 2012, p. 349 (and the employees have to understand what they are doing successfully and what they are not (Lussier and Hendon 2012, p. 288).

3. Outputs, the form of the performance appraisal report is the most needed to the development on the clarity, comprehension, and easiness to understand, the suggestions for the better performance, and the description of performance appraisal scores, respectively. The performance management system should aim at achieving employees' behaviors and attitudes to support the organization's strategy, goals, and culture. If a measure does not specify what an employee must do to help the organization achieve its goals, it does not support the strategy. If the measure fails to point out employees' performance problems, they will not know how to improve (Noe et al. 2012, p. 348-350).

4. Feedback has three important characteristics: applying the evaluation results to plan trainings, coaching, making a decision on assigning or transferring duties respectively. Since management is the overriding goal of any appraisal system, appraisal should be more than a past-oriented activity that criticizes or praises workers for their performance in the preceding year. Rather, appraisal must take a future-oriented view of what workers can do to achieve their potential in the organization. This means that managers must provide workers with feedback and coach them to higher levels of performance. (Gomez-Mejia et al .2012, p. 223).

\subsection{Guidelines for the Development of the Performance Appraisal System}

1. The input must include the clear workload as well as the collective agreement of the indicators and evaluation criteria between supervisors (evaluators) and evaluates (government employees). Job analysis is logically our first step because if we don't know what a job consists of, how can we possibly evaluate an employee's performance (Lussier and Hendon 2012, p. 286). The form used in the evaluation must cover both performance and operational behaviors. There should be an additional comment section for evaluators and respondents, Scoring Rubrics, Holistic Rubrics, and Analytic Rubrics. The evaluation should be objective, not subjective. Employees need to know the standards and understand what good performance looks like, and they need to be able to measure their own performance (Lussier and Hendon 2012, p. 295-296).

2. The process of performance appraisal should be conducted in the manner of evaluations with the committee with a systematic follow-up of performances. The ratings from all evaluators are reviewed. Due to all areas of our people management process, we must make sure that all of our performance management tools are valid and reliable. If our method of measurement is not valid and reliable, then it makes no sense to use it. When a measure has validity, it is a factual measure that measures the process that you wanted to measure. A reliable measure is consistent; it works in generally the same way each time we use it) Lussier and Hendon 2012, p. 287-288. (Whether or not a measure is valid and reliable, it must meet the practical standard of being acceptable to the people who use it (Noe et al. 2012, p. 348-35).

3. The outputs of the performance appraisal report must clearly show the scores from the indicators, scoring rubric, and examples to support the evaluation results, so the result can be more reliable and more accepted. Suggestions should be presented to tell the evaluator what to observe by adding sections of good and must-improved behaviors since evaluation and measure must be specific enough to identify what is going well and what is not as well as to provide enough information for everyone to understand about what level of performance has been achieved by a particular employee within a well-identified job (Lussier and Hendon 2012, p. 287-288).

4. The feedback can divide government employees into 3 groups. The first group is very good and excellent. The focus must be on the recognition of the past performance. The second group is good and fair. The feedback must be provided on both sides (good and bad) while focusing on what should be improved. The last group is must-improve. The focus is on what is needed to be improved to make the performances better as soon as possible. All government employees must, then, write a plan to improve their operations. Since feedback is an important part of the education process, test grades let students know what they have achieved and what they must learn to do better next time. People at work give feedback to reinforce others' good behavior and correct their poor behavior. The recipient of feedback judges its value and determines whether to accept and act on the feedback, reject it, or ignore it (London 2003, p. 11). 


\section{Suggestions}

\subsection{Suggestions for the Applications of the Findings}

1. According to the findings of this study, the government officers of the Provincial Statistical Office (evaluators) have played a very important role in the development of the performance appraisal system for government employees to make the system fair and reliable. Unless the evaluator uses the evaluation without manipulating the evaluation, it does not matter how well the system is. The organization without an effective evaluation may suffer from losses. Therefore, it will be the best if there is a process to educate the government officers as well as to create a corporate culture on the correct performance appraisal system.

2. The findings suggest that the feedback is needed for the development of training and coaching plans for government employees, especially in the application of the results from the evaluation because the feedback creates opportunity for government employees to review and correct their practice. The Provincial Statistical Office can also apply the feedback for planning, training, coaching, or targeting the development of the future evaluations. Consequently, the involved person must be aware of the importance of the results from the evaluations by applying them to personnel development plans and job transfers besides the process of considering Pay for Performance, or lay off.

3. The findings identify the limitations of the performance appraisal system for government employees by asking questions about what the problem is and where the problem of system is. The priorities are determined. Now? involved decision makers can effectively apply the results of this study to the development of the performance appraisal system for government employees at the Provincial Statistical Office.

\subsection{Suggestions for the Further Study}

1. The training needs assessment model for government employees at the Provincial Statistical Office should be examined in order to identify those who need training and what kind of trainings is needed for Provincial Statistical Office to be suitable training programs to meet the needs of the government employees.

2. The feedback model on the performance appraisal results at Provincial Statistical Office should be studied to help government employees improve their performance and consider opportunities for development in order to be motivated to demonstrate behaviors contributing to the successful performance.

3. The evaluation of the evaluator (government officers) model (or meta-evaluation) should be studied to obtain information relevant to the development of skill evaluation for government officers in order to ensure the total process being carried out in a fair, professional and credible manner

\section{Reference}

Altschuld, J. W., \& Kumar, D. D. (2010). Needs assessment: An overview. Thousand Oaks, CA: Sage Publications.

Dessler, G. (2013). Fundamentals of human resource management. Upper saddle River, NJ: Prentice Hall.

Diane A. (2008). Performance Appraisals: Strategies for Success. New York: American Management Association.

Gomez-Mejia, L. R., Balkin, D. B., \& Cardy R. L. (2012). Managing human resources (7th ed.). Upper saddle River, NJ: Prentice Hall

Krejcie, R. V., \& Morgan, D. W. (1970). Determining sample size for research activities. Educational and Psychological Measurement, 30(3), 607-610. https://doi.org/10.1177/001316447003000308

London, M) .2003 .(Job feedback :Giving, seeking, and using feedback for performance improvement .(2nd ed.). Mahwah, NJ: Lawrence Erlbaum.

Lussier, R. N., \& Hendon, J. R. (2012). Human resource management: Functions, applications, and skill development. Thousand Oaks, CA: Sage Publications.

Mathis, R. L., \& Jackson, J. (2010). Human resource management: Essential perspectives. (13th ed.). Mason, OH: Cengage Learning.

Mondy, R. W., \& Martocchio, J. J. (2012). Human resource management. (12th ed) . Upper Saddle River, NJ: Pearson Higher Education.

National Statistical Office. (2015) Strategic plan for human resource management. National Statistical Office, annual budget 2014-2017. Bangkok: National Statistical Office (Pamphlet)

Noe, R. A., Hollenbeck, J. R., Gerhart, B., \& Wright, P. M. (2012). Fundamentals of human resource management. (4nd ed.). New Yok: McGraw-Hill/Irwin.

Sleezer, C. M., Russ-Eft, D., \& Gupta, K. (2014). A practical guide to needs assessment. (3rd ed.). San Francisco, CA : 
John Wiley \& Sons. https://doi.org/10.1002/9781118826164

Watkins, R., Meiers, M. W., \& Visser, Y. (2012). A guide to assessing needs: Essential tools for collecting information, making decisions, and achieving development results. Washington, DC : World Bank Publications. https://doi.org/10.1596/978-0-8213-8868-6

Wongvanich, S. (2015). Research on needs assessment. (3rd ed.). Bangkok : Chulalongkorn University.

\section{Copyrights}

Copyright for this article is retained by the author(s), with first publication rights granted to the journal.

This is an open-access article distributed under the terms and conditions of the Creative Commons Attribution license which permits unrestricted use, distribution, and reproduction in any medium, provided the original work is properly cited. 